\title{
THE SYRIAN CRISIS REPERCUSSIONS ON THE PHARMACEUTICAL INDUSTRY: ANALYTICAL FIELD STUDY
}

\author{
Dr. Abdullah Hamada
}

\begin{abstract}
The pharmaceutical industry in Syria underwent a major significant decline, affecting negatively the needs of the Syrian citizen from drugs and vaccines, in which the effect of the current Syrian crisis on the pharmaceutical industry has a great damage to the right of the Syrian citizen in the availability of suitable medication and treatment, and the right of children for a vaccine that helps to avoid many of the diseases that affect their future and growth.

The current crisis in Syria has contributed significantly to the great decline in the proportion of indications, treatment, and the lack of drugs, in which the pharmaceutical industry is concentrated in the hottest areas in Syria, the thing that led to a severe shortage of drugs in the Syrian pharmaceutical market.
\end{abstract}

Key Words: Syrian, Syrian Crisis, Pharmaceutical Industry

\section{INTRODUCTION: ANALYTICAL FIELD STUDY ON THE PHARMACEUTICAL INDUSTRY}

\subsection{The Research Problem}

After thirty-three months of the current crisis in Syria, the pharmaceutical industry sector, in all its aspects, has been sabotaged and destroyed, and serious damage has hit the pharmaceutical factories in Aleppo, Homs, and rural Damascus, where about $90 \%$ of the pharmaceutical factories in the country are located. Thus, pharmaceutical factories that used to manufacture local drugs have stopped working in these most damaged areas, which led to a severe shortage of drugs and medical supplies in Syria, and a significant rise in the prices of drugs in the light of the current crisis in Syria.

\subsection{The Research Objective}

This research aims to identify the most important possible support strategies, in order to contribute to the rehabilitation of pharmaceutical factories to work again, and take its essential role in securing the urgent needs of drugs for citizens.

\subsection{The Importance of The Research}

The importance of this research rises from its looking into the most important factors that contributed to the significant decline in the production of 
drugs and the damage done to pharmaceutical factories, such as the destruction caused by bombing, the theft of raw materials, hazardous working conditions, as well as other factors.

\subsection{Research Methodology}

This research relies on a descriptive analytical method, which is based on field data collection and analyzing it using the *SPSS program.

\subsection{Sample and Research Limits}

This study included data for 25 pharmaceutical factories, and these factories constitute most of the factories located in the studied area.

\subsection{The Reality of The Pharmaceutical Sector in Syria Before The Crisis}

Data of the Central Bureau of Statistics in Syria in 2010, listed in Table (1), show that the number of the productive pharmaceutical factories in Syria (public and private) has reached 70 plants in 2010, in an annual growth rate of $6.5 \%$ during the period of 2006 to 2010. Only two of these factories are public sector (Tamiko - AlDimas), and the rest are of the private sector, as shown in Figure (1), except that the geographical distribution of these factories is concentrated in three provinces that are Aleppo by $40 \%$, Damascus and its countryside by $40 \%$, and Homs by $20 \%^{18}$, as shown in Figure (2).

Figure 1:The Contribution of The Private Sector in The Pharmaceutical Sector

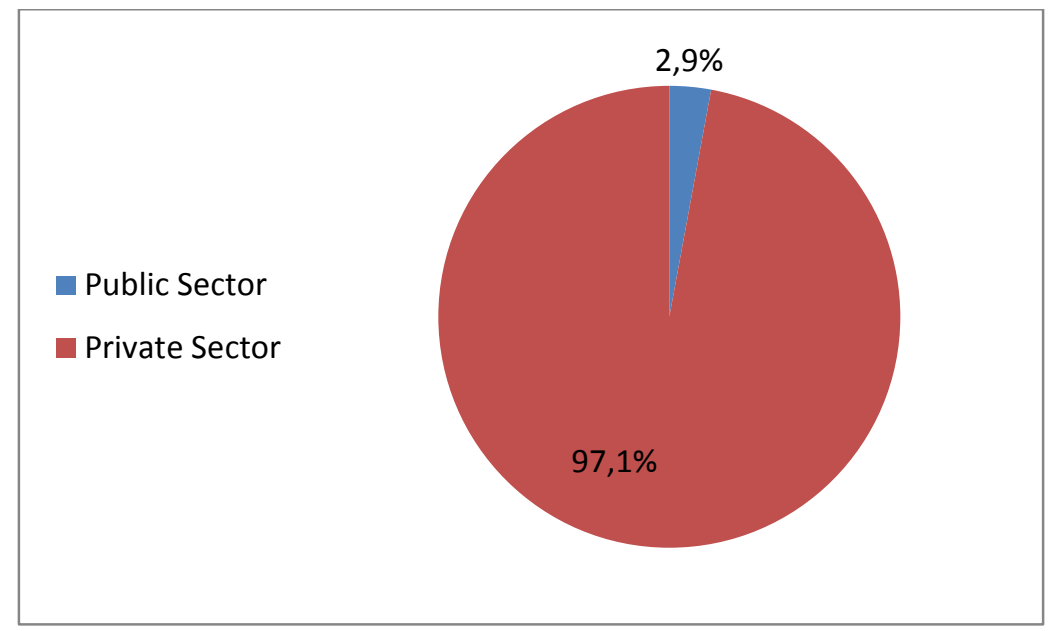

${ }^{18} \mathrm{http}: / /$ arabic.arabianbusiness.com/politicseconomics/2013/feb/19/324092/\#.UsCfnfTI WU to view 30-12-2013 
Figure 2:The Distribution of Pharmaceutical Factories in Syria According to Provinces

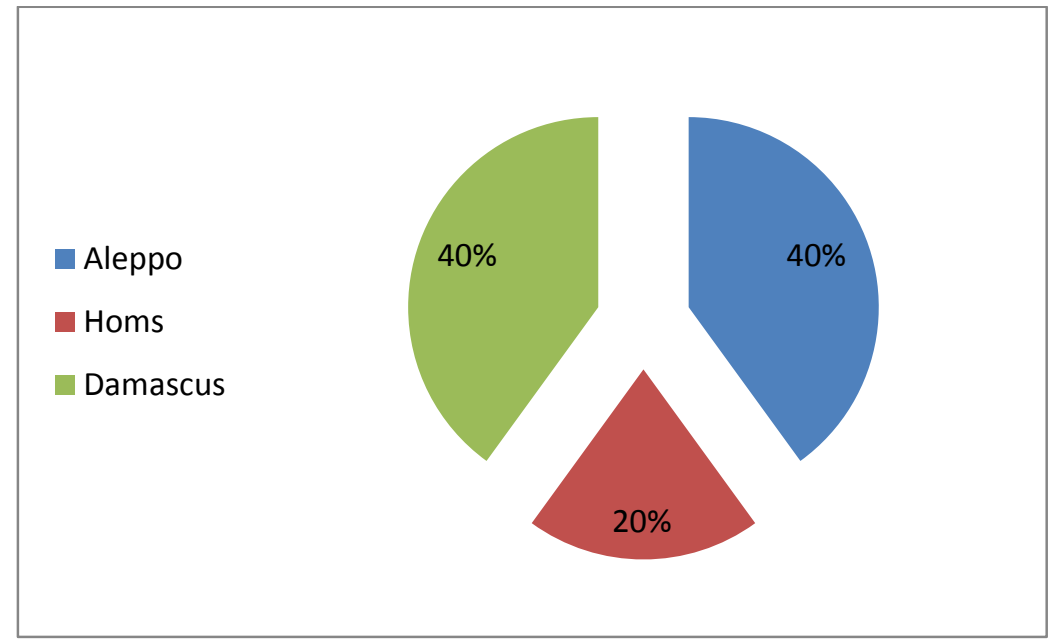

In recent years, the pharmaceutical industry in Syria has witnessed a remarkable development, for it covered more than $91 \%$ of the local market's need, especially psychiatric, dermal, gynecological, and ophthalmic medications and children's syrup, with an annual growth rate of $3 \%$ during the period from 2006 to 2010. Moreover, the number of licensed pharmaceutical items in Syria has reached to 6895 item in 2010, with an annual growth rate of 5\% during the period from 2006 to 2010. All but except for blood derivatives, cancer drugs, and vaccines that are all imported through barter protocols, yet the prices were suitable for all society's groups.

Table 1: Pharmaceutical Industry Data in Syria During The Period From 2006 to 2010

\begin{tabular}{|c|c|c|c|c|c|}
\hline Year & $\mathbf{2 0 0 6}$ & $\mathbf{2 0 0 7}$ & $\mathbf{2 0 0 8}$ & $\mathbf{2 0 0 9}$ & $\mathbf{2 0 1 0}$ \\
\hline Classification & 5709 & 5860 & 6168 & 6381 & 6895 \\
\begin{tabular}{c|c|c|c|} 
Number of Pharmaceutical \\
Items Manufactured Locally
\end{tabular} & 63 & 66 & 67 & 70 \\
\hline $\begin{array}{c}\text { Number of Local } \\
\text { Pharmaceutical Factories }\end{array}$ & 56 & 90 & 90 & 90 & 91 \\
\hline $\begin{array}{c}\text { Local Pharmaceutical Coverage } \\
\text { Ratio of The Pharmaceutical } \\
\text { Overall \% }\end{array}$ & 90 &
\end{tabular}

The Source: Central Bureau of Statistics, Statistical Abstract 2011, table 1/12.

The Syrian pharmaceutical industry has created over the past years an economic power that employed around thirty thousand workers, and secured most of the local market's needs of drugs, and then exported to dozens of 
countries all over the world. Moreover, recent statistics of the Union of the Arab Pharmaceutical Producers noted that Syria is one of the most recent Arab countries that has widely entered the field of pharmaceutical industry, however, it was able to achieve quantum leaps that made it occupy the second place among Arab countries in covering its local need after Egypt, as well as the second Arab country after Jordan in the volume of exports of medicines. At this point, it is worth of mentioning that the Syrian drug in some markets such as Yemen and Iraq is number one, and there are 57 countries in Asia, Africa, and Eastern Europe that the Syrian pharmaceutical products have reached, as well as international organizations such as the UNICEF and the World Health Organization $^{19}$.

\subsection{The Reality of The Pharmaceutical Sector in Syria During The Crisis}

After a two and half years for this terrible crisis in Syria, the pharmaceutical sector in its various aspects was subjected to sabotage and destruction, which led to the closure of many of the factories that manufactured local drugs, and therefore an acute shortage of medicine, and the entry of many foreign drugs at high prices. All that rendered the citizen in front of a great hindrance in receiving his right to treatment. Moreover, the economic recession, the subordination of the black market to international prices, and the low purchasing power of the Syrian currency have contributed in a major crisis worthy of rapid intervention by the countries of the world, the World Health Organization, and by the government as well, to find out the difficult pharmaceutical status endured by the Syrian citizen.

The domestic market has witnessed the loss of certain types of drugs, and the most important of those missing types are those related to deadly and chronic diseases, and the patient is required to take it regularly. Yet, what raises panic among patients is that the alternatives of these drugs cannot achieve the same pharmaceutical effect, and the most important of these drugs are: "Nitroglycerin" for minor strokes attack, "Daflon" for veins' disorders and the inflammation of veins, "Altroxan, Thiamasul" a medicine for the thyroid gland, "asthma sprays" Vlozon with its measurements, Azmirol, as well as cardiac patches "Netroderm", and most of these types are necessary with no alternative.

World Health Organization (WHO) has indicated that the events in Syria have caused the shutdown of a large number of pharmaceutical factories, and serious damage to factories in Aleppo, Homs, and rural Damascus, which led to a shortage of chronic diseases medications, and that there is an urgent need to TB, hepatitis, high blood pressure, diabetes, and cancer drugs, as well as medical supplies in Syria ${ }^{20}$.

Medecins Sans Frontieres (MSF) has described the health situation in Syria as devastated, and it stated in its report that the medical aid and many of the hospitals are being destroyed and attacked directly, and that many workers

\footnotetext{
${ }^{19}$ A Report For The Minister of Health in Syria, about the reality of the pharmaceutical sector in Syria, published in the http://tishreen.news.sy/tishreen/public/read/250701 Website, viewed on 30-12-2013.

${ }^{20}$ Report talking about the loss of a number of drugs in the local market in Syria, published in the http://aliqtisadi.com Website, dated 1-7-2013, viewed on 30-12-2013.
} 
in the field of hospitalization and health have been hurt. It advocated through its report to facilitate the entry of medical and pharmacokinetics aid to the Syrian territory, and confirmed the spread of many contagious and infectious diseases because of poor pharmaceutical situation in Syria, and that is through a system applied to monitor contagious diseases ${ }^{21}$.

Alternatively, the General Manager of Medico factory has stated that they have stopped the manufacture of some medicines due to the lack in its raw materials, such as drugs allocated for the treatment of migraine, and that the first concern of the pharmaceutical factories in recent times is to secure raw materials, stressing the lack of support for these materials despite the repeated promises they were given, adding that the difficulty in obtaining these materials, the high costs to redeem the goods at customs, which has doubled six times, and the high prices of supplementary materials of glass, plastic, and cardboard have made pharmaceutical factories on the verge of bankruptcy ${ }^{22}$.

The Chairman of the Federation of Syrian Chambers of Industry has warned that the vast majority of pharmaceutical factories will have to shut down production for about $70 \%$ of the bio-pharmaceutical types that are produced normally, because the current exchange rates will lead to higher costs to the extent that production costs will be collected at higher prices than the ones specified by the Syrian Ministry of Health. The Chairman of the Union has pointed out that these factories are on the verge of bankruptcy, and therefore this situation is the beginning of a real disaster, presented in the lack of the locally made drug, and the entry of smuggled drugs that price up to at least five times the local, noting that it's an unreliable medication in its quality because it is smuggled, and one may not know where it came from nor its origin ${ }^{23}$.

Some activists and citizens in hot areas have also confirmed that the regime's shells do not exclude pharmaceutical factories in Aleppo and Homs in particular, which led to the destruction of large parts of them. Citizens have also complained of the soaring prices of drugs, and furthermore, recently a phenomenon of cheating in most types has emerged, and local drugs are being secretly sold as foreign, and exploiting the people's need for the drug in addition to the presence of smuggled drugs of unknown origins.

This is a synopsis of the suffering of the Syrian pharmacological reality, but will this deterioration continue until it becomes like other commodities, which have vanished from the markets, and insane rising prices, or are there solutions in the near horizon?

\subsection{Some of The Actions Taken by The Government to Resolve The Pharmaceutical Crisis}

In front of the reality of the suffocating pharmaceutical crisis citizens wonder in general, and the sick and their families in particular, about the actions that the government has undertaken to find urgent solutions to maintain the national pharmaceutical industry, and to ensure the continuity of covering the

\footnotetext{
21 - Http://sns.sy/sns/?path=news/read/65417 to view 30-12-2013

22 A report on the reality of the pharmaceutical sector in Syria, published in the http://tishreen.news.sy/tishreen/public/read/250701 Website, viewed on 30-12-2013.

23 - Http://breakingnews.sy/ar/article/17676.html, to view 30-12-2013
} 
market's need of local drugs, in terms of manufacturing, distribution, transportation, and prices, down to fit all Syrians during or after the current circumstances.

In the shadow of the Syrian pharmaceutical system vacillation between the shortage of some drugs, and the loss of about $75 \%$ of the pharmaceutical varieties in Damascus and its countryside ${ }^{24}$, and stoppage of production for about $60 \%$ of the factories, and the remaining ones being on the verge of bankruptcy, the Chairman of the Scientific Council of Pharmaceutical Industries has clarified that since the beginning of the crisis that Syria is exposed to, a code of honor was signed by the owners of the pharmaceutical factories, including their pledge in not claiming any raise in prices during the crisis, nor laying off any workers, and maintaining production and distribution as much as possible. Factory owners have committed to this pledge for only 22 months from the age of the crisis, but the shortage of stocks of raw materials and the dollar reaching high levels prevented working by this code of honor, moreover it caused some factories to stop production once and for all, which made us sound the alarm over the fate of the pharmaceutical future of Syria ${ }^{25}$.

The Chairman of the Scientific Council of the Pharmaceutical Industry in Syria has reclaimed the government to act and take decisions away from tossing responsibility. There is no solution but to secure raw materials in order to continue production or raise the prices of drugs to cover the cost which soared with the high exchange rate of the dollar, the thing that the owners of pharmaceutical factories do not take responsibility of. Because of the continuous rising of the exchange rate and the central bank cease of financing imports of the needed raw materials to manufacture the drug in the local factories, this industry have become threatened to shut down, which simply means the layoff of tens of thousands of workers and therefore joining those unemployed, and the shift to importing drugs in amounts that would reach more than a billion and a half billion dollars annually.

In the context of tackling these questions, the government studied those demands through the ministries of health and the economy in a joint meeting, and discussed through it the mechanisms to facilitate the import of raw materials, the needed supplies for the pharmaceutical industry, and the difficulties and challenges associated with them in the light of the current crisis, in which ensures the maintenance of pharmacotherapy security. Yet despite the long time passed for this meeting, the necessary decisions were never issued, thus, adding to the concerns and fears of drug producers.

The Deputy Minister of Health pointed out that the government is aware of the magnitude of the pharmaceutical problem, and tries as much as possible to overcome this crisis, for we have tried in the beginning to cover the shortfall with alternatives, «the same active ingredients, but with different trade names»

\footnotetext{
${ }^{24}$ Report of the Director of Health rural Damascus, Free Palestine Agency - Agencies, published on the link, http://www.palestineafree.com/index.php?id=4993 \#. UsVNdvRdVWU, to view 30-12-2013.

${ }^{25}$ Report entitled: Will the government wake up and the central bank for the drug security? dated 15-6-2013 published on the electronic link, http://www.syriasteps.com/?d=144\&id=105941\&in_main_page=1 viewed 30-12-2013.
} 
from different undamaged factories, that manufacture products with the same chemical compositions for the missing drugs, and we have taken some action when the market began to suffer from a shortage in drugs, such as opening the door to importing drugs that used to be manufactured locally but became insufficient with no local alternatives, in addition to some important steps, namely: coordinating with all concerned parties to secure the movement of drugs in the market, manufacture, distribute, or transfer, and to secure energy resources «fuel and electricity» for the pharmaceutical factories. All that is in order for them not to stop, in cooperation with the relevant ministries, and to allow hospitals and medical bodies in all ministries to directly purchase the drugs that are unavailable in the markets, and are not registered in the Ministry of Health, especially cancer drugs ${ }^{26}$.

However, the government had earlier allowed the moving of facilities and industrial factories, in whole or in part, from the hot spots to other safe ones, and that is to preserve the continuity of the production process, and to provide the necessary facilities for industrialists. In addition to focusing on the possibility of the creation or moving of pharmaceutical factories to the provinces of Tartous and Lattakia, since they are considered be safe areas.

In the midst of the aggravation of the drug dilemma in Syria, the Minister of Health has also clarified that the Syrian government has signed last January with the Iranian side an agreement on a line of credit of one billion dollars and that the share of the Ministry of Health of this loan amounted to 200 million dollars, bearing in mind that this amount is insufficient to meet the large needs of the health sector under the current circumstances ${ }^{27}$

Alternatively, some pharmaceutical factories' owners have offered their doubts about the ability of the private sector to take advantage of this loan and the flexibility of the transactions and procedures in this field. Most factories' owners have stressed that despite what they have suffered, they did not and will not dismantle and deport their factories to Tartous, rather they will continue to work in their place.

However, some pharmaceutical factories' owners in Syria have pointed out the marginalization of their role by the government to participate in decisions, and they said we are the last to know about any decision taken by the government, and we find ourselves forced to cope with this procedure or that, for we are supposed to be the decision-makers, especially that our role is fundamental in securing medications.

The media spokesman for the World Health Organization Tariq Jassarevich has stated: The medical facilities that have stopped working are located in the heart of the hottest areas, in which the importance of medical and surgical interventions increase. And if the Syrian regime, until this moment, refuses to recognize the magnitude of the damage announced by the World

\footnotetext{
${ }^{26}$ A previously mentioned report entitled: Will the government wake up and the central bank for the drug security?? dated 15-6-2013 published on the electronic link, http://www.syriasteps.com/?d=144\&id=105941\&in_main_page=1 viewed 30-12-2013.

${ }^{27}$ A report for the Minister of Health entitled: no real drug problem in Syria, and work is undergoing to secure the missing items. Posted on the electronic link, www.syrianow.sy/index.php?d=48\&id=5069 viewed on 30-12-2013.
} 
Health Organization in its report, the Chairman of the Federation of Chambers of Syrian Industry holds the government responsible for the deterioration of the Syrian pharmaceutical sector, in a statement to one of the Syrian media he explained the government's negligence, saying: in Aleppo alone, more than twenty factories, which its production covers $50 \%$ of the local market's needs, have been shut down, and it was possible to avoid such closure if the province of Aleppo and the government had responded to the numerous demands and appeals that were launched by the Aleppo Chamber of Industry and the industrial and economic activities in the city, to ensure the protection of the industrial city and the pharmaceutical factories!.

He also pointed out that the impact of the closure of the pharmaceutical factories will soon be evident on the entire local drug market in Syria ${ }^{28}$.

But despite these efforts, reality remains terrible, as evident by the decline in manufacturing the drug locally, due to the exit of many pharmaceutical factories from the production process, or reducing the production of those left, the failure in manufacturing raw materials used in the composing Syrian drugs locally, the poor distribution of drugs to pharmacies, the difficulty of transferring them between a number of provinces, the loss of many varieties of drugs, such as cancer drugs, serums, and asthma sprays, and the high prices of drugs, to a degree that a large proportion of patients are unable to purchase, despite the urgent need for the drug, and the entry of smuggled drugs with unknown quality and effectiveness ..., etc.

To stand upon the reality of pharmaceutical factories, and the reasons for diminishing or stopping their production, despite the urgent need for different drugs, we will undergo the following analytical study.

\subsection{The Analytical Study}

After viewing the reality of the pharmaceutical industry in Syria before and after the current crisis, it was clear that this large pharmaceutical dilemma is worsening and growing, and the acute shortage in the production of pharmaceutical factories is increasing. Thus, a thorough look should be made at the data of the reality of pharmaceutical factories in the liberated areas, that are suffering more from the drugs crisis. The following is a presentation of the reality of these factories.

\subsection{The Size of The Pharmaceutical Factories}

We will present the reality of the pharmaceutical factories through their area, ownership, and management.

\subsubsection{Area:}

Table (2) shows that the factories which area is larger than 400 square meters have reached $76 \%$, whereas the factories which area is between 200 and

\footnotetext{
${ }^{28}$ Report entitled: Pharmacies even lacked the Iranian supported drug... and pharmacists of Damascus are selling their last stocks. Date 4-12-2012,

Posted on the link, http://www.zamanalwsl.net/PrinterFriendlyVersion.php?id=30361 viewed on 30-12-2013.
} 
400 square meters have reached $20 \%$, and there are a $4 \%$ of factories with areas less than 200 square meters.

Table 2:Distribution of Pharmaceutical Factories According to Area

\begin{tabular}{|c|c|c|}
\hline Factory Area & $\begin{array}{c}\text { Number of } \\
\text { Factories }\end{array}$ & Percentage \% \\
\hline Less than 200 square meters & 1 & 4.0 \\
Between 200-400 square meters & 5 & 20.0 \\
More than 400 square meters & 19 & 76.0 \\
Overall & 25 & 100.0 \\
\hline
\end{tabular}

\subsubsection{Ownership}

Table (3) shows that the factories owned by one person reach almost $92 \%$ of the majority of the pharmaceutical factories surveyed, while factories that are owned by more than one person stood at $4 \%$, and there are $4 \%$ of factories with undefined ownership.

Table 3:Distribution of Pharmaceutical Factories According to Ownership

\begin{tabular}{|c|c|c|}
\hline Type of Ownership & $\begin{array}{l}\text { Number } \\
\text { of Factories }\end{array}$ & age $\%$ \\
\hline Sole owner & 23 & 92.0 \\
\hline $\begin{array}{l}\text { More than one } \\
\text { owner }\end{array}$ & 2 & 4.0 \\
\hline Other & 2 & 4.0 \\
\hline Overall & 25 & 100.0 \\
\hline
\end{tabular}

\subsubsection{Management}

As for the distribution of factories according to their management, it is shown in Table (4), in which factories were classified into those that are managed by their owners, which reached $92 \%$, and the others are not.

Table 4:Distribution of Pharmaceutical Factories According to Management

\begin{tabular}{|c|c|c|}
\hline $\begin{array}{c}\text { Factory } \\
\text { Management }\end{array}$ & $\begin{array}{r}\text { Numbe } \\
\text { r of Factories }\end{array}$ & e\% \\
\hline Factory owner & 23 & 92.0 \\
Other & 2 & 8.0 \\
Overall & 25 & 100.0 \\
\hline
\end{tabular}

\subsection{The Operational Status of Pharmaceutical Factories}

We will present the reality of pharmaceutical factories in terms of readiness to operate, the readiness of machines, and the availability of raw materials. 


\subsubsection{Readiness of Factories:}

Table (5) and Figure (3) show that the status of the pharmaceutical factories is very good by a percentage of $72 \%$, good by a percentage of $16 \%$, and medium by a percentage of $12 \%$.

Table 5: Distribution of Pharmaceutical Factories According to Status

\begin{tabular}{|l|c|c|}
\hline Factory Status & $\begin{array}{c}\text { Number } \\
\text { of Factories }\end{array}$ & Percentage \\
\hline Medium & 3 & 12.0 \\
Good & 4 & 16.0 \\
Very Good & 18 & 72.0 \\
Overall & 25 & 100.0 \\
\hline
\end{tabular}

Figure 3: Ratios of Pharmaceutical Factories Distribution According to Status, Readiness of Machines, and Availability of Raw Materials

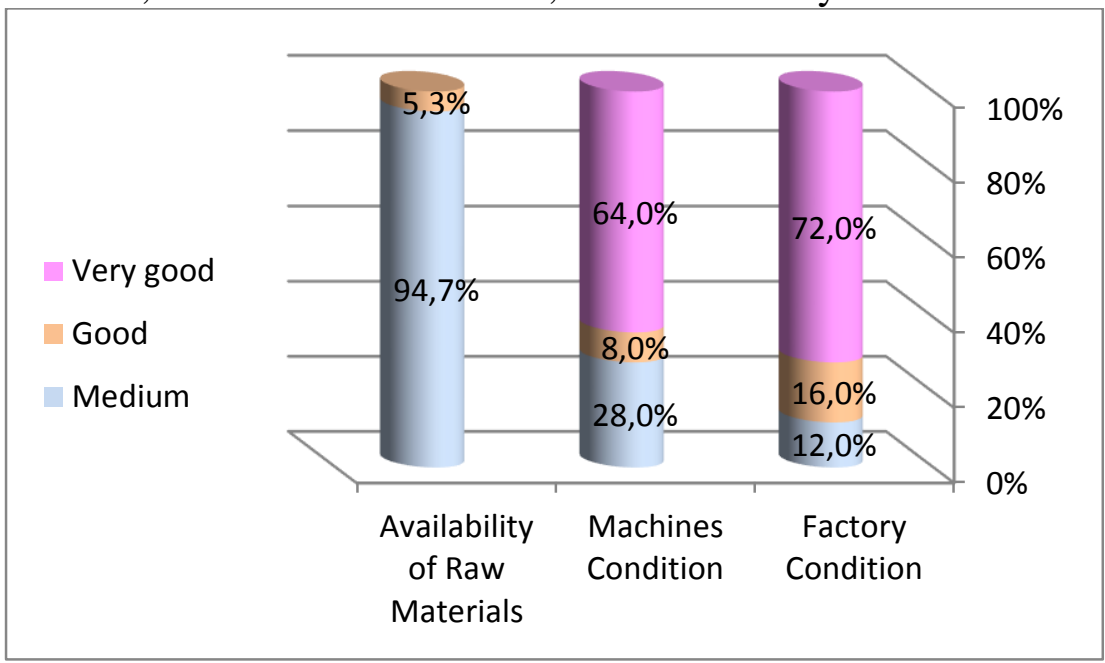

\subsubsection{Readiness of Machines:}

Table (6) and Figure (3) show that the readiness of the machines in pharmaceutical factories is very good by a ratio of $64 \%$, good by a ratio of $8 \%$, and medium by $28 \%$.

Table 6: Distribution of Pharmaceutical Factories According to Readiness of Machines

\begin{tabular}{|c|c|c|}
\hline $\begin{array}{c}\text { Readiness of } \\
\text { Machinery }\end{array}$ & $\begin{array}{c}\text { Number of } \\
\text { Factories }\end{array}$ & Percentage \\
\hline Medium & 7 & 28.0 \\
Good & 2 & 8.0 \\
Very Good & 16 & 64.0 \\
Overall & 25 & 100.0 \\
\hline
\end{tabular}




\subsubsection{Availability of Raw Materials:}

Table (7) and Figure (3) show that the availability of raw materials in the pharmaceutical factories is medium and bad by a percentage of $94.7 \%$, and good by $5.3 \%$.

Table 7: Distribution of Pharmaceutical Factories According to Availability of Raw Materials

\begin{tabular}{|l|c|c|}
\hline Availability of Raw Materials & $\begin{array}{c}\text { Number of } \\
\text { Factories }\end{array}$ & Percentage \\
\hline Medium & 18 & 94.7 \\
Good & 1 & 5.3 \\
Total of those who clarified & 19 & 100.0 \\
Overall & 25 & \\
\hline
\end{tabular}

\subsubsection{Sources of Raw Materials}

Table (8) shows that most factories rely on raw materials' sources that are obtained from Arab countries by a percentage of $76 \%$, and sources from other countries by $24 \%$.

Table 8: Distribution of Pharmaceutical Factories According to Sources of Raw

Materials

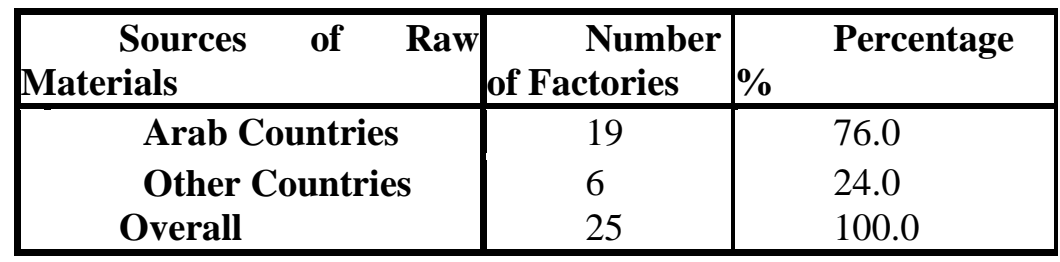

\subsection{Workers of Pharmaceutical Factories}

We will present the situation of workers in pharmaceutical factories through their number during the crisis, the ratio of unemployment brought about by the crisis, and their distribution according to specialty.

\subsubsection{Number of Workers During The Crisis}

Table (9) and Figure (4) show that the number of factories, in the sample studied, with less than 10 workers had amounted $16 \%$, whereas factories with 11-20 workers amounted to $4 \%$, and factories with $21-50$ workers reached $8 \%$, which means that, on the one hand, small factories with less than 50 workers reached $28 \%$, while, on the other hand, medium-sized factories with 51-200 workers reached $44 \%$, and factories with more than 200 workers, i.e. large in terms of the number of workers, reached $28 \%$. 
Table 9: Distribution of Pharmaceutical Factories According to Number of Workers

\begin{tabular}{|l|c|c|}
\hline Number of Workers & $\begin{array}{r}\text { Numb } \\
\text { Factories }\end{array}$ & Percentag \\
\hline $\mathbf{e \%}$ & \\
\hline $\mathbf{1 - 1 0}$ & 4 & 16.0 \\
$\mathbf{1 1 - 2 0}$ & 1 & 4.0 \\
$\mathbf{2 1 - 5 0}$ & 2 & 8.0 \\
$\mathbf{5 1 - 1 0 0}$ & 2 & 8.0 \\
$\mathbf{1 0 1 - 2 0 0}$ & 9 & 36.0 \\
More than 200 & 7 & 28.0 \\
Overall & 25 & 100.0 \\
\hline
\end{tabular}

Figure 7: Distribution of Pharmaceutical Factories According to Number of Workers

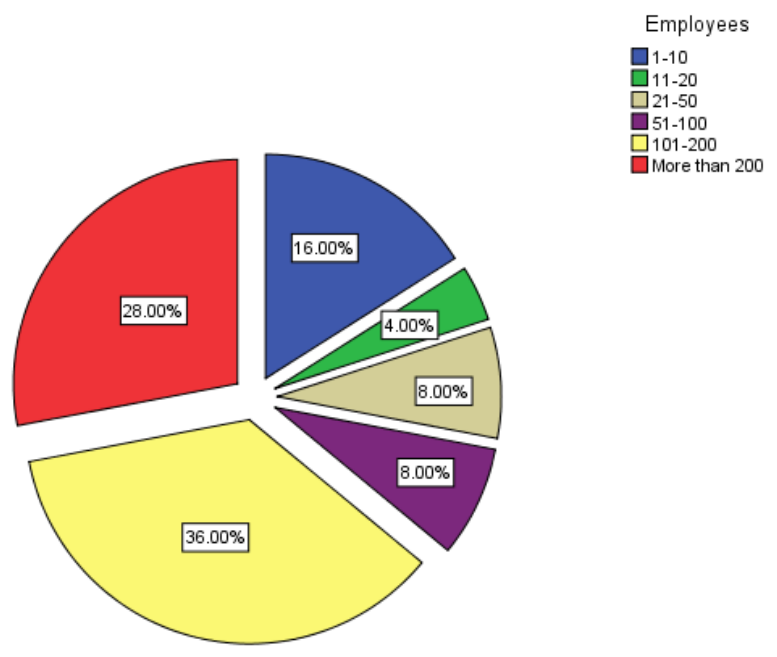

\subsubsection{Unemployment Rate}

We calculated the average number of studied pharmaceutical factories' workers who were registered before the crisis, and it reached about 156 workers. During the study period, the average number of workers attending in factories had reached 5 workers, which means that the unemployment rate of the labor of pharmaceutical factories reached $85 \%$, as shown in the table (10). 
Table 10:The Average Number of Workers In Factories Before and After The Crisis, and The Proportion of The Unemployed

\begin{tabular}{|l|l|c|}
\hline Workers & Average & $\begin{array}{c}\text { Standar } \\
\text { d deviation }\end{array}$ \\
\hline Current number of workers & 4.28 & .358 \\
Number of workers before the crisis & 155.56 & 22.100 \\
The previous unemployment rate & $\% 85.02$ & .06142 \\
\hline
\end{tabular}

\subsubsection{Distribution by Specialty}

As for Figure (5), it displays the distribution of workers by specialty, and the largest percentage was the ratio of skilled workers, reaching $60.6 \%$, while the percentage of management personnel reached $20.5 \%$, the percentage of ordinary workers reached $15.7 \%$, and the rest are specialists and technicians by a percentage of almost $3.2 \%$.

Figure 5: Distribution of Pharmaceutical Factories' Workers According to

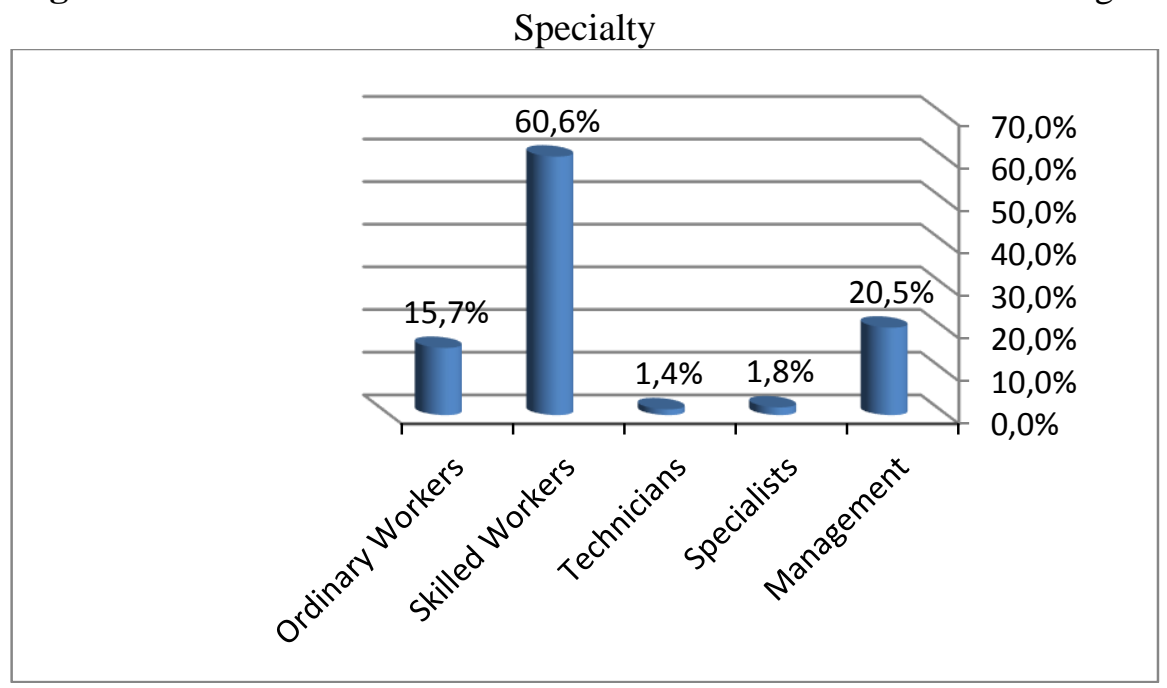

\subsubsection{Salaries And Wages}

Table (11) shows that the percentage of factories that pay wages on a regular basis amounted to $24 \%$, and factories that paid irregularly amounted to $76 \%$.

Table 11: Distribution of Pharmaceutical Factories According to Payment of Salaries Status

\begin{tabular}{|c|c|c|}
\hline $\begin{array}{c}\text { Payment of Salaries } \\
\text { Status }\end{array}$ & $\begin{array}{c}\text { Number of } \\
\text { Factories }\end{array}$ & Percentage\% \\
\hline Regularly & 6 & 24.0 \\
Irregularly & 19 & 76.0 \\
Overall & 25 & 100.0 \\
\hline
\end{tabular}




\subsubsection{Working Hours}

Table (12) shows that the percentage of factories working full time amounted to only $16 \%$, factories working part-time amounted to $12 \%$, while the factories that do not work at all amounted to $72 \%$.

Table 12: Distribution of Pharmaceutical Factories According to Working

\begin{tabular}{|c|c|c|}
\hline Hours Status & $\begin{array}{c}\text { Number of } \\
\text { Factories }\end{array}$ & Percentage\% \\
\hline Work Full time & 4 & 16.0 \\
Work Part-time & 3 & 12.0 \\
Do not work & 18 & 72.0 \\
Overall & 25 & 100.0 \\
\hline
\end{tabular}

\subsection{Basic Services In Pharmaceutical Factories}

We will present the reality of the basic services in pharmaceutical factories through the perspective of their owners regarding the provision of basic services, such as the deportation of waste, emergency services, and transportation services.

\subsubsection{Waste Deportation}

Table (13) and Figure (6) show that most factories answer the service of deporting waste with "often" has reached $88 \%$, but a significant minority indicated that they have insufficient opportunities for waste deportation service by a ratio of $12 \%$, that they "rarely" get a waste deportation service.

Table 13: Availability of Waste Deportation Service From The Viewpoint of Factory Owners

\begin{tabular}{|c|c|c|}
\hline $\begin{array}{c}\text { Status of Waste } \\
\text { Deportation }\end{array}$ & $\begin{array}{c}\text { Number of } \\
\text { Factories }\end{array}$ & Percentage\% \\
\hline Often & 22 & 88.0 \\
Rarely & 3 & 12.0 \\
Overall & 25 & 100.0 \\
\hline
\end{tabular}


Figure 6: Availability of Basic Services From The Perspective of Factory Owners

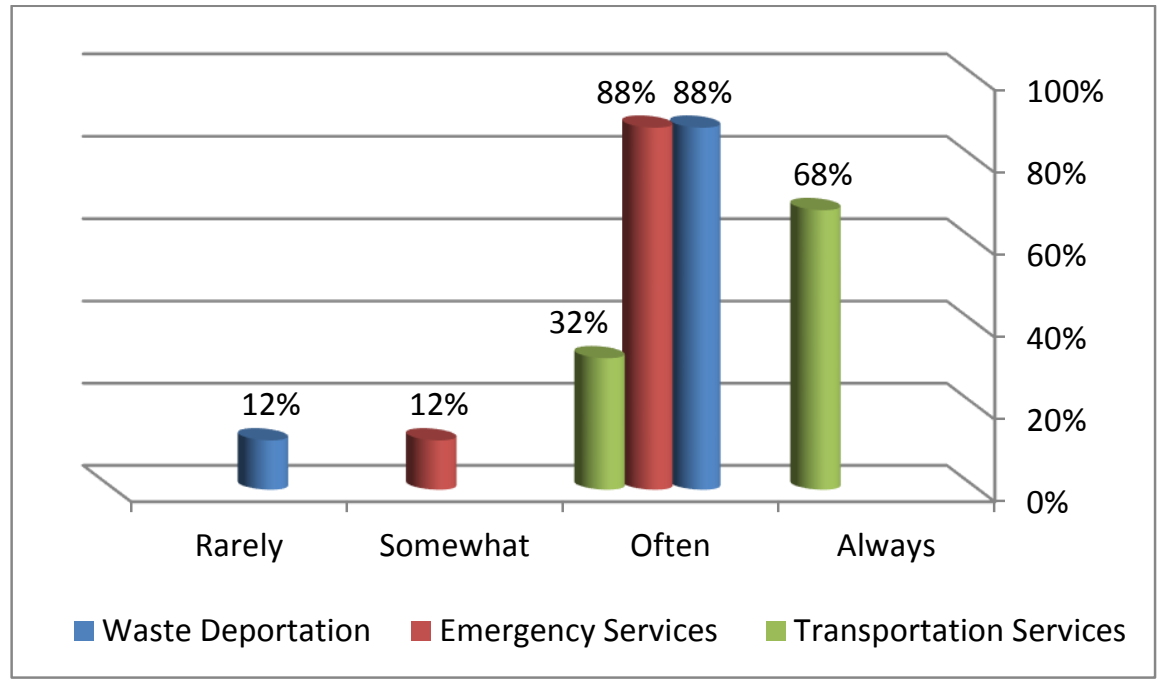

\subsubsection{Emergency Services}

Table (14) and Figure (6) show that most factories that answer the availability of emergency services with "often" has reached $88 \%$, but a significant minority said they were "somewhat" getting emergency services by a percentage of $12 \%$.

Table 14: Availability of Emergency Services From The Standpoint of Factory Owners

\begin{tabular}{|c|c|c|}
\hline $\begin{array}{c}\text { Availability of } \\
\text { Emergency Services }\end{array}$ & $\begin{array}{c}\text { Number of } \\
\text { Factories }\end{array}$ & Percentage\% \\
\hline Often & 22 & 88.0 \\
Somewhat & 3 & 12.0 \\
Overall & 25 & 100.0 \\
\hline
\end{tabular}

\subsubsection{Transportation Services:}

Table (15) and Figure (6) show that most factories that confirmed the availability of transportation services and answered with "always" amounted to $68 \%$, while those answered with "often" amounted to $32 \%$. 
Table 15: Availability of Transportation Services From The Viewpoint of Factory Owners

\begin{tabular}{|c|c|c|}
\hline $\begin{array}{c}\text { Availability of } \\
\text { Transportation } \\
\text { Services }\end{array}$ & $\begin{array}{c}\text { Number of } \\
\text { Factories }\end{array}$ & Percentage\% \\
\hline Always & 17 & 68.0 \\
Often & 8 & 32.0 \\
Overall & 25 & 100.0 \\
\hline
\end{tabular}

\subsection{Basic Dynamic Energy (Electricity) in Pharmaceutical Factories}

We will present the reality of the need for electricity, its sources, and usage hours during the crisis.

\subsubsection{The Need For Electricity}

In terms of the usage of electricity, studies have showed that $96 \%$ of factories depend on electricity as the basic dynamic energy for their production processes, and cannot do without it, as shown in the table (16).

Table 16: Distribution of Pharmaceutical Factories According to The Need For Electricity

\begin{tabular}{|c|c|c|}
\hline $\begin{array}{c}\text { Use } \\
\text { Electricity }\end{array}$ & \begin{tabular}{|l|l|} 
ber & Num \\
Factories & of
\end{tabular} & Percentage \\
\hline No & 1 & 4.0 \\
\hline Yes & 24 & 96.0 \\
\hline Overall & 25 & 100.0 \\
\hline
\end{tabular}

\subsubsection{Sources of Access to Electricity}

Most pharmaceutical factories were classified as factories that get electricity through the state's public network and it's percentage reached $76 \%$, while other factories that obtain electricity through private or shared generators with several other factories amounted to $24 \%$, as shown in the Table (17).

Table 17: Distribution of Pharmaceutical Factories According to Sources of Access To Electricity

\begin{tabular}{|c|c|c|}
\hline $\begin{array}{l}\text { Sources of Access to } \\
\text { Electricity }\end{array}$ & $\begin{array}{r}\text { Number } \\
\text { of Factories }\end{array}$ & Percentage \\
\hline $\begin{array}{l}\text { Electrical } \\
\text { generators }\end{array}$ & 6 & 24.0 \\
\hline $\begin{array}{l}\text { Public network } \\
\text { Overall }\end{array}$ & $\begin{array}{l}19 \\
25\end{array}$ & $\begin{array}{l}76.0 \\
100.0\end{array}$ \\
\hline
\end{tabular}

\subsubsection{Hours of Electricity Usage}

As for the periods of the use of pharmaceutical factories for electricity, it has been classified as shown in table (18) 1- Most factories that use electricity on a daily basis for less than three hours reached $80 \%$, 2- Factories that use 
electricity for 3-6 hours per day reached $8 \%, 3$ - And factories that use electricity for 6-12 hours per day reached $12 \%$.

Table 18: Distribution of Pharmaceutical Factories According to The Number of Hours of Electricity Usage

\begin{tabular}{|l|c|c|}
\hline Electricity Usage & $\begin{array}{c}\text { Number of } \\
\text { Factories }\end{array}$ & Percentage\% \\
\hline Less than 3 hours & 20 & 80.0 \\
Between 3-6 & 2 & 8.0 \\
Between 6-12 & 3 & 12.0 \\
Overall & 25 & 100.0 \\
\hline
\end{tabular}

\subsection{Safety in Pharmaceutical Factories:}

We will present the security status of the areas where pharmaceutical factories are located, and the dangers they can be exposed to, from the standpoint of their respective owners.

\subsubsection{The Proportion of Safety}

Table (19) shows the status of safety from the standpoint of factory owners. They were described by a percentage of $88 \%$ that they are located in relatively secure areas, $8 \%$ that they are located in relatively dangerous areas, and $4 \%$ that they are located in seriously dangerous areas.

Table 19: Distribution of Pharmaceutical Factories According to Security Status

\begin{tabular}{|c|c|c|}
\hline Safety Status & $\begin{array}{c}\text { Number of } \\
\text { Factories }\end{array}$ & Percentage\% \\
\hline Relatively safe & 22 & 88.0 \\
Relatively dangerous & 2 & 8.0 \\
Very dangerous & 1 & 4.0 \\
Overall & 25 & 100.0 \\
\hline
\end{tabular}

\subsubsection{Artillery Fire Risk}

As for the types of risks, each type was separately discussed. Table (20) and Figure (7) show that a percentage of $92 \%$ of pharmaceutical factories' owners have confirmed the existence of the danger of artillery fire.

Table 20: Danger of Artillery Fire From The Viewpoint of Factory Owners

\begin{tabular}{|c|c|c|}
\hline Artillery Fire Risk & $\begin{array}{c}\text { Number of } \\
\text { Factories }\end{array}$ & Percentage\% \\
\hline No Danger & 2 & 8.0 \\
Danger & 23 & 92.0 \\
Overall & 25 & 100.0 \\
\hline
\end{tabular}




\subsubsection{Aircraft Bombing Risk}

As for the danger of aerial bombardment, Table (21) and Figure (7) show that a percentage of $24 \%$ of pharmaceutical factories' owners have confirmed the existence of the risk of aerial bombardment, and this ratio is much less than the risk of artillery fire.

Table 21: The Risk of Aerial Bombardment From The Viewpoint of Factory Owners

\begin{tabular}{|c|c|c|}
\hline $\begin{array}{c}\text { Aerial Bombardment } \\
\text { Risk }\end{array}$ & $\begin{array}{c}\text { Number of } \\
\text { Factories }\end{array}$ & Percentage\% \\
\hline No Danger & 19 & 76.0 \\
Danger & 6 & 24.0 \\
Overall & 25 & 100.0 \\
\hline
\end{tabular}

\subsubsection{Armed Groups Risk}

As for the danger of armed groups, Table (22) and Figure (7) show that a ratio of $76 \%$ of pharmaceutical factories' owners have confirmed that there is no risk of armed groups, while $24 \%$ have confirmed the existence of the risk of armed groups.

Table 22: The Risk of Armed Groups From The Standpoint of Factory Owners

\begin{tabular}{|c|c|c|c|c|}
\hline Risk & Armed Groups & $\begin{array}{c}\text { Number } \\
\text { of Factories }\end{array}$ & $\%$ & Percentage \\
\hline & No Danger & 19 & & 76.0 \\
\hline & Danger & 6 & & 24.0 \\
\hline & Overall & 25 & & 100.0 \\
\hline
\end{tabular}

Figure 7:Types of Risks From The Standpoint of Factory Owners

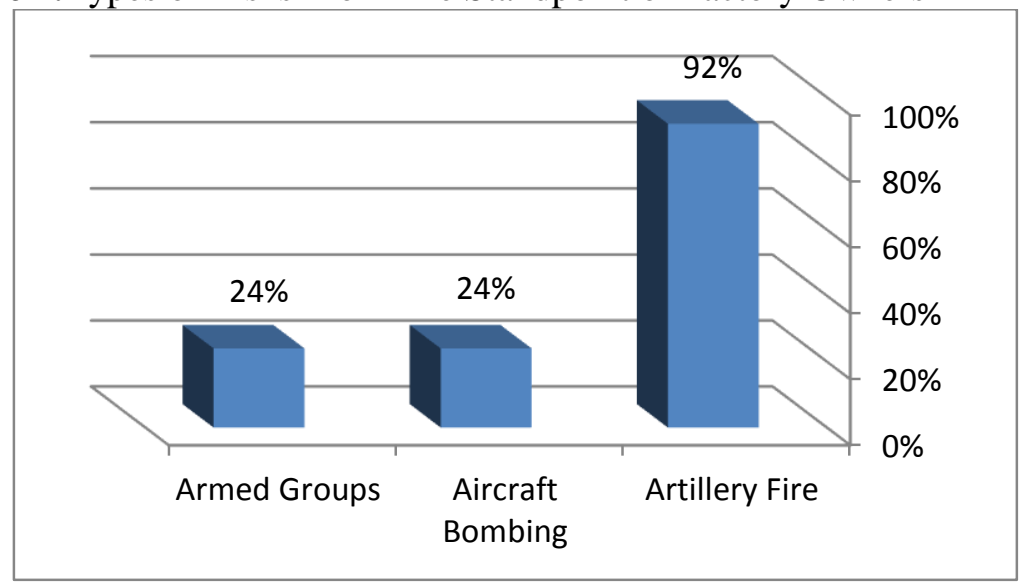

We note that there is a contradiction between the pharmaceutical factories' owners two points of view, first: $88 \%$ of them confirmed that their factories are located in places somewhat safe, second: $92 \%$ of them have confirmed the existence of the danger of artillery fire. 
One possible explanation is that the owners of these factories do not consider themselves in dangerous areas because they are located in liberated areas, thus, they are not in direct contact with danger, despite their acknowledge that the possibility of artillery fire reaching is big.

\subsection{Production in Pharmaceutical Factories}

\subsubsection{Production Ratios}

Table (23) and Figure (8) show that there is a very large proportion of pharmaceutical factories, estimated by $76 \%$ of factories, that no longer produce, and that $4 \%$ of the factories produce less than a quarter of its production capacity, as well as $12 \%$ produce less than half of its production capacity, and only $8 \%$ of the factories produce its usual before-conflict capacity, while $8 \%$ of factories have undefined production.

Table 23: Distribution of Pharmaceutical Factories According to Production Ratios

\begin{tabular}{|c|c|c|}
\hline Production Ratio & $\begin{array}{c}\text { Number of } \\
\text { Factories }\end{array}$ & Percentage\% \\
\hline $\mathbf{0 \%}$ & 19 & 76.0 \\
$\mathbf{1 - 2 4 \%}$ & 1 & 4.0 \\
$\mathbf{2 5 - 4 9 \%}$ & 2 & 8.0 \\
$\mathbf{1 0 0 \%}$ & 1 & 4.0 \\
Undefined & 2 & 8.0 \\
Overall & 25 & 100.0 \\
\hline
\end{tabular}

Figure 8: Distribution of Pharmaceutical Factories According to Production Ratios
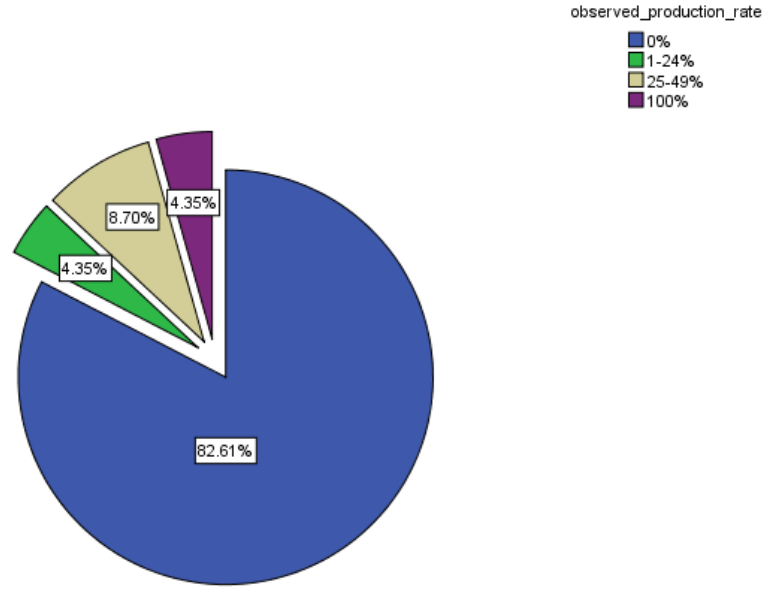


\subsubsection{Distribution of Products}

As for Figure (9), it shows that $96.65 \%$ of the production of pharmaceutical factories is for the domestic market, and the proportion of $4.35 \%$ of the production is for export. We note that at the present time, pharmaceutical factories targeted local markets in the first place.

Figure 9: Distribution of Pharmaceutical Factories According to Target Market

$$
\begin{gathered}
\text { target_market } \\
\square \text { Internal } \\
\square \text { Exporting }
\end{gathered}
$$

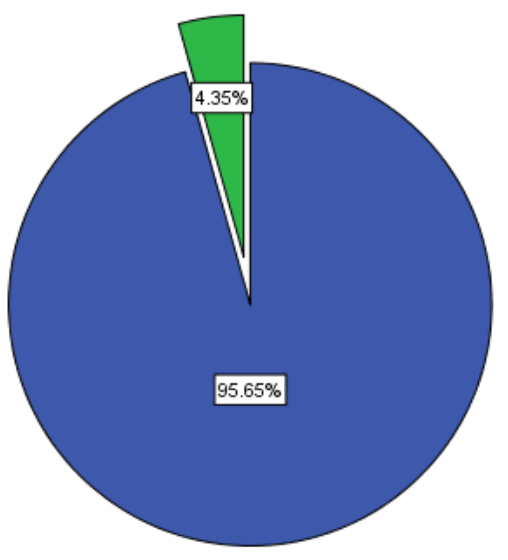

\section{SUMMARY OF THE ANALYTICAL STUDY}

It was obvious, through the analytical study of the reality of pharmaceutical factories, that $76 \%$ of the factories do not produce at all, and this coincides with the World Health Organization report about the stoppage of a large number of pharmaceutical factories to produce, and the acute shortage of drugs, despite the urgent need (report dated 01/07/2013). This result is also in line with the report of MSF on the collapsed health situation in Syria (report dated 07/26/2013), and it also complies with the report of the Chairman of the Federation of Chambers of Industry in Syria regarding the cease of production of more than $70 \%$ of pharmaceutical items (report dated 20/05/2013). This may be due to the following reasons:

A. Availability of Raw Materials: The proportion of $97.4 \%$ of pharmaceutical factories' owners confirmed that the status of availability of raw materials is medium, as shown in Table (7), which means that a large part in the decline in productivity is due to the lack of raw materials in the required quantities.

B. Productivity normally decreases with the decrease of working hours, and Table (12) shows that $72 \%$ of factories do not work at all, which is the main reason for the decline in productivity.

C. Out of the study of electricity we noted that $96 \%$ of factories rely mainly on electricity, and $80 \%$ of them use electricity for less than 3 hours, which 
means that whenever the hours of electricity usage decrease, productivity reduces.

D. Security Status: The state of artillery and aviation bombardment also reflect low productivity, in which a proportion of $92 \%$ of the owners of pharmaceutical factories have confirmed the existence of the risk of artillery fire, $24 \%$ have confirmed the existence of the risk of aerial bombardment, and $24 \%$ have confirmed the existence of the risk of armed gangs, as shown in Figure (7).

E. Number of Workers: Low productivity is due to the decrease in the number of workers, in which Table (10) shows that the unemployment rate in pharmaceutical factory workers amounted to $85 \%$.

F. The dramatic decline in the percentage of workers, technicians, and specialists may lead to a decline in productivity, this percentage has reached $3.2 \%$ in pharmaceutical factories, which is a very low percentage when compared with their counterparts in the developed countries that exceed $60 \%$.

G. Salaries And Wages: Part of the decline in production is due to the irregular distribution of salaries, in which the proportion of factories that pay salaries irregularly has reached $76 \%$, as shown in Table (11).

\section{CONCLUSION AND RECOMMENDATIONS}

Pharmaceutical industry used to contribute in covering the domestic market by a percentage of $91 \%$, reducing the import of drugs, and employing workers. Given the current crisis and the lack of security stability in Syria, the intervention to help the pharmaceutical factories in Syria is still risky, however, in the light of previous findings, we can offer the following recommendations:

1. It should be stressed, in every possible way, to stop the aerial bombardment and artillery shelling, to pursue armed gangs which carry out operations of theft and looting, and to achieve a higher rate of safety appropriate for the re-operating of factories.

2. Pharmaceutical factories must be supported through continuously securing raw materials at discounted prices, and directing all pharmaceutical products to meet the urgent needs of local citizens.

3. A recommendation to international banks to support and finance the importation of raw materials for the manufacture of medicines, specially for factories in areas outside the control of the regime.

4. The study of the foundations of pricing and adjusting it with accordance to the income of the citizens in these compelling circumstances.

5. Work should be done on reforming public electricity networks, and securing suitable electrical generators for factories.

6. Support pharmaceutical factories to work in its utmost production capacity and employ all workers, and pay their salaries on a regular basis, in order to provide them with a sufficient income to live a decent life, be able to secure their basic needs, and do not think to leave their homes and flee to other places inside or outside Syria. 
7. Finally, Urging pharmaceutical factories on the rehabilitation and training of workers in accordance to the former's need of specialties and technical skills, in order to get international certificates of good drug manufacturing in Syria.

\section{REFERENCES}

A previously mentioned report entitled: Will the government wake up and the central bank for the drug security?? dated 15-6-2013 published on the electronic link, http://www.syriasteps.com/?d=144\&id=105941\&in_main_page=1 viewed 30-12-2013.

A report for the Minister of Health entitled: no real drug problem in Syria, and work is undergoing to secure the missing items. Posted on the electronic link, www.syrianow.sy/index.php?d=48\&id=5069 viewed on 30-12-2013.

A Report For The Minister of Health in Syria, about the reality of the pharmaceutical sector in Syria, published in the http://tishreen.news.sy/tishreen/public/read/250701 Website, viewed on 30-12-2013.

A report on the reality of the pharmaceutical sector in Syria, published in the http://tishreen.news.sy/tishreen/public/read/250701 Website, viewed on 30-12-2013.

Central Bureau of Statistics, 2011, Statistical Abstract 2011. http://arabic.arabianbusiness.com/politicseconomics/2013/feb/19/324092 /\#.UsCfnfTI WU to view 30-12-2013

Http://breakingnews.sy/ar/article/17676.html, to view 30-12-2013

Report entitled: Will the government wake up and the central bank for the drug security?? dated 15-6-2013 published on the electronic link,http://www.syriasteps.com/?d=144\&id=105941\&in_main_pag $\mathrm{e}=1$ viewed 30-12-2013.

Report of the Director of Health rural Damascus, Free Palestine Agency Agencies, published on the link,http://www.palestineafree.com/index.php?id=4993 \#. UsVNdvRdVWU, to view 30-12-2013.

Report talking about the loss of a number of drugs in the local market in Syria, published in the http://aliqtisadi.com Website, dated 1-72013, viewed on 30-12-2013.

Report entitled: Pharmacies even lacked the Iranian supported drug... and pharmacists of Damascus are selling their last stocks. Date 4-122012, Posted on the link, http://www.zamanalwsl.net/PrinterFriendlyVersion.php?id=30361 viewed on 30-12-2013. 